\title{
Apolipoproteína E e a doença de Alzheimer
}

\author{
Elida P. Benouigue Ojopi \\ AlEXANDRE BRUno Bertoncini \\ Emmanuel Dias Neto*
}

\begin{abstract}
Resumo
Sabemos hoje que os polimorfismos no gene da apolipoproteína E (apoE) são importantes fatores de risco para o desenvolvimento da doença de Alzheimer (DA). O gene apoE humano, mapeado no braço longo do cromossomo 19 (19q13.2), codifica uma glicoproteína com 317 aminoácidos, a qual desempenha um papel fundamental para o catabolismo de componentes ricos em triglicérides no corpo humano. Em humanos, existem três alelos principais do gene apoE, decorrentes de apenas duas alterações no DNA, chamados de $\varepsilon 2$, $\varepsilon 3$ e $\varepsilon 4$. A identificação da variante $\varepsilon 4$ do gene apoE como o fator genético de risco mais comum para a DA de início tardio sugere que o colesterol deva ter um papel direto na patogênese da doença. Contudo, a simples presença do alelo apoE $\varepsilon 4$ não é necessária nem suficiente para causar DA; este alelo apenas aumenta o risco de o indivíduo vir a desenvolver a doença, indicando que existem outros fatores ambientais e genéticos importantes no desenvolvimento da mesma.
\end{abstract}

Palavras-chave : Doença de Alzheimer, APOE, Apolipoproteína E

\begin{abstract}
It is known that polymorphisms in the gene of the apolipoprotein $\mathrm{E}$ (apoE) are important risk factors in the development of the Alzheimer's disease (AD). The human gene apoE, which is mapped in the long arm of chromosome 19 (19q13.2), codes for a glycoprotein with 317 amino acids, which plays a basic role for the catabolism of triglyceride-rich components in the human body. In our species the apoE gene appears in the form of three main alleles, produced from two alterations in the DNA sequence, called $\varepsilon 2, \varepsilon 3$ and $\varepsilon 4$. The identification of the variant $\varepsilon 4$ of gene apoE as the most relevant genetic marker for the risk for late-onset $\mathrm{AD}$ suggests that cholesterol may have a direct involvement in the pathogenesis of this disease. However, apoE $\varepsilon 4$ is not necessary nor enough to cause Alzheimer's disease. It only increases the risk of an individual to develop the illness, indicating that other environmental/genetic factors shoud play important roles in the development of the disease.
\end{abstract}

Key Words : Alzheimer' disease, APOE, Apolipoproteína E

Recebido: 17/11/2003 - Aceito: 26/11/2003

Laboratório de Neurociências (LIM-27), Instituto de Psiquiatria, Faculdade de Medicina, Universidade de São Paulo.

* Pesquisador e vice-diretor do Laboratório de Neurociências (LIM27).

Endereço para correspondência: Laboratório de Neurociências (LIM27), Instituto de Psiquiatria, Hospital das Clínicas, Faculdade de Medicina da Universidade de São Paulo (HC-FMUSP), Rua Dr. Ovídio Pires de Campos, s/n, Cerqueira César. CEP 05403-010, São Paulo - SP, Brasil. Telefone: (11) 3069-7267; FAX: (11) 3062-4851; E-mail: emmanuel@usp.br 


\section{Genética e biologia da DA}

Há muito, é reconhecido que a doença de Alzheimer (DA) pode ocorrer com maior freqüência em algumas famílias. Esta observação, apesar de não excluir a importância dos fatores ambientais, constitui um dos primeiros indícios de que fatores genéticos pudessem ter influência no desenvolvimento da doença. Desta forma, o encontro de alterações de DNA, características de indivíduos portadores da doença, poderia fornecer um marcador biológico importante. O encontro deste marcador vem sendo o alvo de numerosos grupos internacionais na pesquisa recente.

A DA de início precoce foi associada, até o momento, a mutações em genes que codificam para a proteína precursora da $\beta$-amilóide (APP: $\beta$-amyloid precursor protein - 21q21.3), presenilina 1 (PSEN1: presenilin 1 - 14q24.3) e presenilina 2 (PSEN2: presenilin 2 - 1q31q42). As mutações nesses genes são responsáveis por aproximadamente $40 \%$ dos casos de DA com início precoce (revisão em Tanzi e Bertram, 2001). Porém, a DA de início precoce foge do padrão da doença, em que cerca de 95\% dos casos ocorrem com início tardio. Nestes casos, o espectro de mutações é distinto. Embora já tenham sido relatados na literatura mais de 30 possíveis marcadores genéticos para a DA de início tardio, até o momento, apenas o alelo $\varepsilon 4$ do gene apoE (19q13.2) mostrou uma associação consistente com a DA em vários estudos independentes (revisão em Laws et al., 2003).

\section{Apolipoproteína E}

O gene apoE humano está localizado no braço longo do cromossomo 19 (19q13.2) (Olaisen et al., 1982; Das et al., 1985; Paik et al., 1985) estando próximo aos genes TOMM40 e apoC1, dentro do loco RELB (Figura 1) (UCSC Genome Browser, http://genome.ucsc.edu/). O apoE é composto por quatro exons, distribuídos ao longo de 6.740 nucleotídeos no genoma humano. Retirando-se os introns, sobram apenas 1.156 pares de bases que compõem o mRNA que será transcrito, responsável pela tradução de três isoformas da proteína. A região transcrita de apoE possui uma grande quantidade de citosinas e guaninas (respectivamente 31,84\% e $37,37 \%$ do mRNA transcrito) que, por formarem três ligações de hidrogênio na dupla fita de DNA, conferem à região uma estabilidade maior, dificultando dessa maneira o processo de amplificação e análise laboratorial deste gene pelo método da PCR (Polymerase Chain Reaction).

A apoE é uma glicoproteína com 317 aminoácidos e é uma das principais proteínas presentes no plasma humano, para onde é exportada após sua síntese no fígado (Lin et al., 1986; Elshourbagy et al., 1985), além de ser a principal apolipoproteína encontrada no cérebro. No plasma, a apoE é o principal componente das lipoproteínas de muito baixa densidade (VLDL) e de um grupo de lipoproteínas de alta densidade (HDL), envolvida na redistribuição de triglicerídeos e coles-

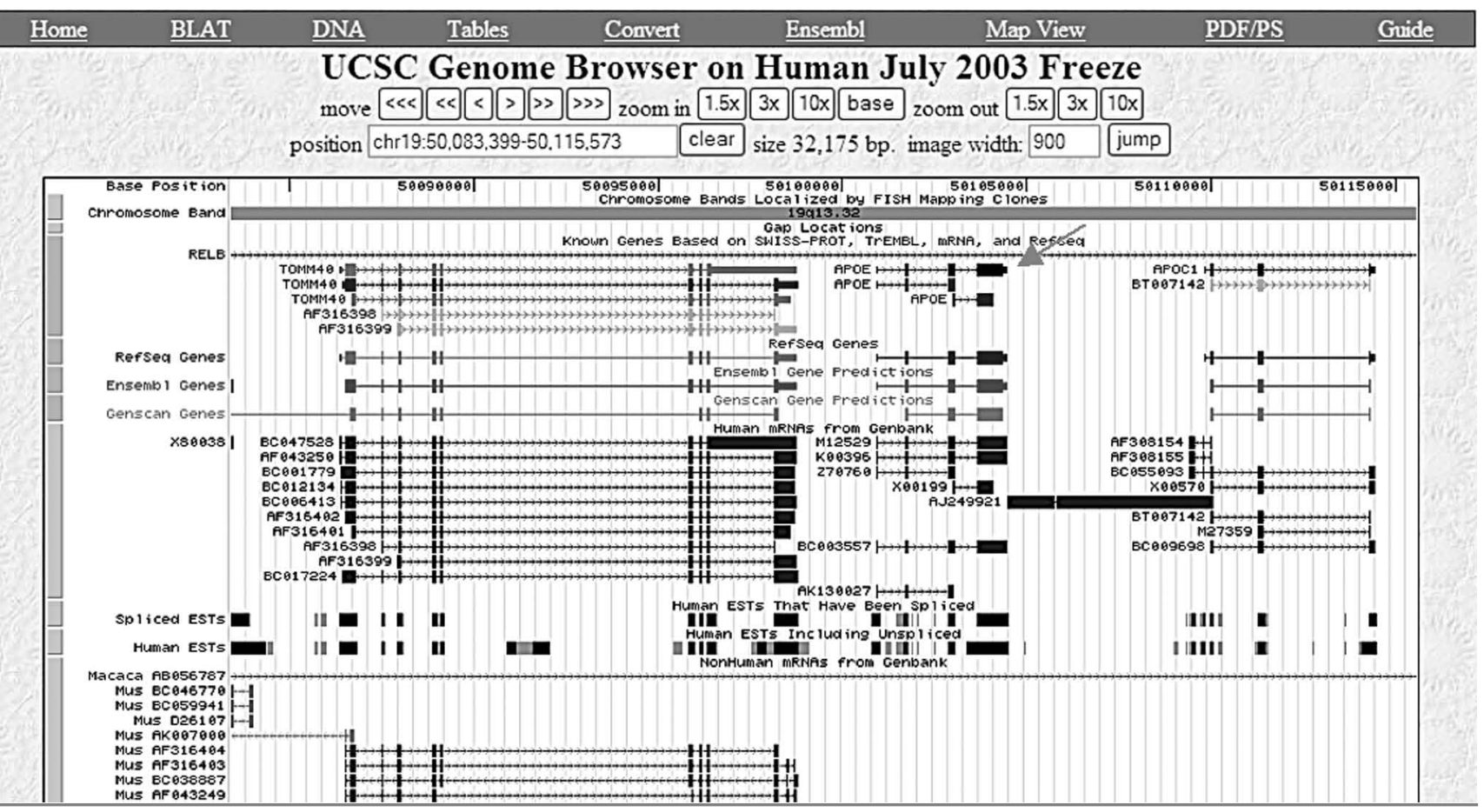

Figura 1: 0 gene apoE humano é composto por quatro exons (seta) e está localizado no braço longo do cromossomo 19 (19q13.2), estando próximo ao genes TOMM40 e APOC1, dentro do loco RELB. 
terol em diferentes tecidos (Mensenkamp et al., 1999). A identificação da variante $\varepsilon 4$ do gene apoE, como o fator genético de risco mais comum para a DA de início tardio, sugere que o colesterol pode ter um papel direto na patogênese da doença.

A apoE é sintetizada em uma grande variedade de tecidos além do fígado, órgão responsável pela produção de cerca de três quartos da apoE circulante no plasma (Elshourbagy et al., 1985; Lin et al., 1986). Nos humanos, o cérebro é o segundo sítio de maior síntese de apoE, sendo produzida principalmente por astrócitos (Boyles et al., 1985; Pitas et al., 1987) e pela micróglia (Nakai et al., 1996). Outros estudos sugerem que, pelo menos sob certas condições, os neurônios humanos podem sintetizar apoE em quantidades significantes (Roses et al., 1998; Xu et al., 1999), possivelmente como uma parte de um programa compensatório para conter a neurodegeneração (Boschert et al., 1999). A apoE é uma das muitas classes diferentes de apolipoproteínas, incluindo apoA, apoB, apoC, apoD e apoJ, as quais transportam lipídios no plasma e em outros fluidos corpóreos.

Comprovando o papel específico da apoE na formação de placas amilóides e emaranhados neurofibrilares, existem estudos mostrando que a apoE é um dos componentes das placas amilóides cerebrais; a apoE4 promove a fibrilogênese in vivo e in vitro do peptídio $\beta$-amilóide e a apoE3 liga-se à proteína Tau, diminuindo a sua taxa inicial de fosforilação e a formação de filamentos (Corder et al., 1998; Czyzewski et al., 1998).

A apoE desempenha um papel fundamental para o catabolismo de componentes ricos em triglicérides no corpo humano. Deficiências dessa proteína causam inúmeras doenças envolvidas com o aumento no nível de colesterol e triglicérides na circulação, devido ao não-reconhecimento dessas moléculas pelos receptores de membrana dos quilomícrons e pelas moléculas de VLDL, responsáveis por sua captação no fígado. Por causar o aumento na concentração dessas substâncias é que a apoE é muito estudada em doenças cardiovasculares, apresentando uma relação direta com estenoses e infartos. A apoE está presente em todas as frações lipoprotéicas do plasma, constituindo de $10 \%$ a20\% das moléculas de VLDL e 1\% a 2\% das moléculas de HDL.

\section{As variantes de apoE}

Durante a evolução, surgiram algumas mutações no gene codificador da apoE. Essas mutações fixaram-se no genoma humano e resultam em genes com peque- nas variações, ou alelos. Estas alterações primárias ocorreram em nível de DNA e resultam em alterações na seqüência da proteína. Em humanos, existem três alelos principais do gene apoE, decorrentes de apenas duas alterações no DNA, chamados de $\varepsilon 2$, $\varepsilon 3$ e $\varepsilon 4$. As isoformas protéicas produzidas por esses alelos diferem na composição de aminoácidos nas posições 112 e/ou 158 (Weisgraber et al., 1981; Rall et al., 1982a,b; Weisgraber et al., 1982): o alelo 22 possui o aminoácido cisteína nas duas posições da proteína (aminoácidos 112 e 158), o $\varepsilon 3$ tem a cisteína na 112 e uma arginina na 158 (sendo este o alelo mais comum da apoE), enquanto que o alelo $\varepsilon 4$ possui argininas nestas duas posições (Figura 2). As outras variantes da apoE são chamadas de $\varepsilon 1$, $\varepsilon 5$ e $\varepsilon 7$, mas elas são extremamente raras.

A natureza polimórfica do gene apoE não é restrita a esses polimorfismos mencionados, os quais definem as três isoformas mais comuns da proteína na população. Foram identificados outros polimorfismos próximos à região promotora (Nickerson et al., 2000; Fullerton et al., 2000), mas a sua importância na DA ainda não foi determinada de maneira consistente.

As várias combinações possíveis de dois dos três alelos principais podem dar origem a seis possíveis genótipos: apoE $\varepsilon 2 / \varepsilon 2$, apoE $\varepsilon 3 / \varepsilon 3$, apoE $\varepsilon 4 / \varepsilon 4$, apoE $\varepsilon 2 / \varepsilon 3$, apoE $\varepsilon 3 / \varepsilon 4$ e apoE $\varepsilon 2 / \varepsilon 4$. A freqüência desses três alelos na população caucasiana em geral é de aproximadamente $8 \%, 78 \%$ e $14 \%$ para o apoE $\varepsilon 2$, apoE $\varepsilon 3$ e apoE $\varepsilon 4$, respectivamente (Utermann et al., 1980; Martins et al., 1995). Corbo e Scacchi (1999) analisaram a distribuição das freqüências alélicas de apoE em diferentes populações e encontraram que o alelo $\varepsilon 3$ é $o$ mais freqüente em todas as populações humanas (variando de $48 \%$ a $89 \%$ ). Nesse estudo, a freqüência do alelo $\varepsilon 4$ só se mostrou elevada ( $24 \%$ a $40 \%)$ em algumas populações (pigmeus, aborígenes da Malásia e Austrália, da tribo de Papua-Nova Guiné, Lapônia e alguns nativos americanos), onde ainda há uma cultura de busca de alimentos, ou a comida ainda é escassa ou o foi até recentemente, ou está disponível de forma esporádica, ou ainda, é qualitativamente pobre.

\section{0 efeito funcional das variantes de apoE}

Um estudo recentemente realizado em ratos procurou elucidar o papel das isoformas $\varepsilon 3$ e $\varepsilon 4$ no catabolismo e metabolismo de HDL, sugerindo que a presença da isoforma $\varepsilon 4$ implica níveis de LDL um pouco elevados no plasma sangüíneo e um pequeno, porém significativo, decréscimo no nível do HDL, inclusive em situações 


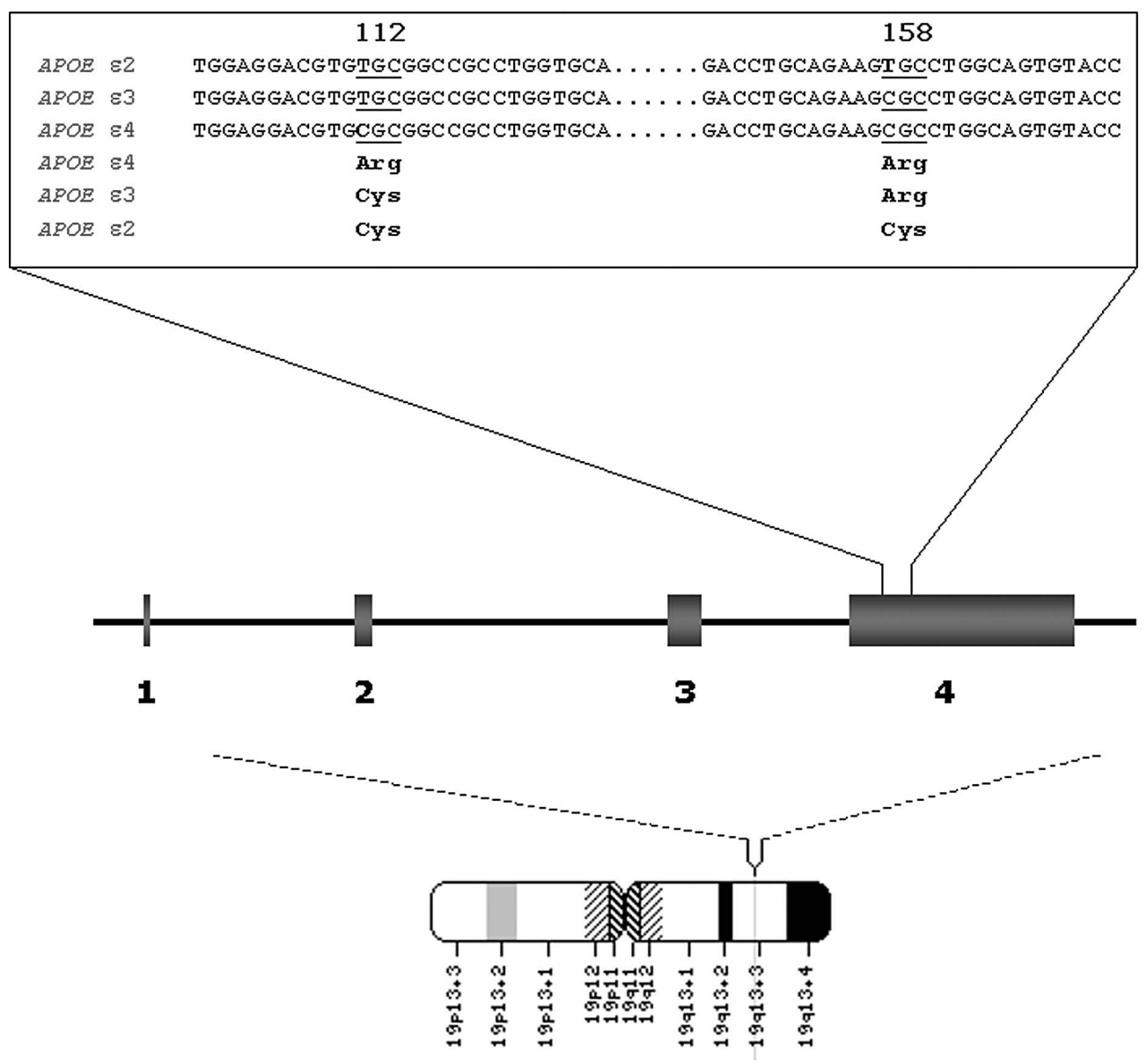

Figura 2: 0 gene apoE humano está mapeado no cromossomo 19 humano (19q13.2). Em humanos existem três alelos principais do gene apoE, chamados de $\varepsilon 2$, $\varepsilon 3$ e $\varepsilon 4$. As isoformas protéicas produzidas por esses alelos diferem na composição de aminoácidos nas posições 112 e/ou 158: ع2 (Cys 112, Cys 158), ع3 (Cys 112, Arg 158), a qual é a forma mais comum, e $\varepsilon 4$ (Arg 112, Arg 158).

nas quais esses animais foram submetidos a uma dieta rica em gorduras (revisão em Puglielli et al., 2003).

Os ratos homozigotos para a isoforma $\varepsilon 4$ apresentaram uma concentração maior de apoE circulante do que aqueles indivíduos heterozigotos $\varepsilon 3 / \varepsilon 4$ que, por sua vez, apresentam níveis maiores que aqueles homozigotos para a isoforma $\varepsilon 3$. Isso sugere que há uma velocidade maior no catabolismo de lipoproteínas em indivíduos portadores do alelo $\varepsilon 4$, quando comparada aos que contêm $\varepsilon 3$. Dessa forma, o nível elevado no catabolismo de remanescentes lipoprotéicos em indivíduos $\varepsilon 4$ pode levar a um déficit dos receptores lipoprotéicos hepáticos, acarretando um aumento no LDL circulante, um dos maiores responsáveis pelo risco de arterioscleroses.

A apoE está intimamente relacionada com outras doenças, como doenças cardíacas (infarto do miocárdio e estenoses de válvulas cardíacas e artérias), hiperlipoproteinemia tipo III, além de condições, nas quais seu papel ainda não foi totalmente elucidado.

\section{ApoE e a DA}

A apoE e a DA foram primeiramente associadas graças a um estudo feito em 1993 na Universidade Duke, onde foi observada uma freqüência maior de apoE $\varepsilon 4$ em pacientes classificados como possíveis ou prováveis portadores da $\mathrm{DA}$, quando comparados com a freqüência observada em indivíduos-controle (Saunders et al., 1993).

O estudo de Corder et al. (1993) foi o primeiro a mostrar que o risco de DA conferido pelo alelo apoE $\varepsilon 4$ aumenta de forma dose-dependente, ou seja, o risco de DA aumenta de $20 \%$ a $90 \%$, e a média de idade de início da doença diminui de 84 para 68 anos com o aumento no número de alelos $\varepsilon 4$. A homozigose para apoE $\varepsilon 4$ chegou a ser declarada como suficiente para desenvolver a doença por volta dos 80 anos de idade. Contudo, o alelo apoE $\varepsilon 4$ não é necessário nem suficiente para causar DA; ele apenas aumenta o risco de o indivíduo desenvolver a doença, indicando 
que existem outros fatores ambientais e genéticos atuando no desenvolvimento da doença (revisão em Rocchi et al., 2003).

Os mecanismos que associam a DA e o alelo apoE $\varepsilon 4$ ainda não foram esclarecidos. Estudos com camundongos transgênicos para o gene APP sugerem que a apoE contribui para o depósito da proteína $\beta$-amilóide $(A \beta)$, sendo este depósito mais severo na presença da isoforma apoE $\varepsilon 4$. A interrupção do gene apoE em camundongos nocaute inibiu a deposição da $\mathrm{A} \beta$ (Bales et al., 1997). A ausência de apoE afetou o acúmulo extracelular da $A \beta$, mas não a sua síntese (Bales et al., 1999).

Existem dois modelos que tentam explicar o papel da apoE no acúmulo da $A \beta$ : no primeiro, a A $\beta$ solúvel interagiria com a apoE associada a uma partícula lipídica, seguindo para a endocitose mediada por receptor. As lipoproteínas são então digeridas enzimaticamente no compartimento lisossômico, liberando o colesterol para a célula. Nos lisossomos, uma fração de apoE-A $\beta$ é degradada, enquanto o restante $\mathrm{da}$ apoE permanece associada à $\mathrm{A} \beta$ e promove a sua agregação em fibrilas amilóides que são secretadas de volta para o meio extra-celular. Dado que a apoE $\varepsilon 4$ tem uma afinidade maior pela $\mathrm{A} \beta$ do que pelas demais isoformas, pode ser esperada uma aceleração nesse processo. No segundo modelo, além de facilitar diretamente a entrada da $A \beta$ na célula e a sua agregação, a apoE poderia também aumentar a taxa de produção de A $\beta$, através do aumento do colesterol celular. Após a endocitose mediada por um receptor e a digestão enzimática das lipoproteínas, o colesterol é liberado para as membranas celulares. As lipoproteínas apoE $\varepsilon 4$ tendem a conter mais colesterol, e o aumento do conteúdo de esterol nas membranas intracelulares promoveria um aumento na taxa de geração de $A \beta$, resultando em uma liberação maior para o meio extracelular (revisão em Puglielli et al., 2003).

Devido à freqüente associação de distúrbios psiquiátricos e a DA, estudos foram feitos com o intuito de verificar se o surgimento e a intensidade desses distúrbios poderiam ser previstos através da tipagem das isoformas de apoE. Como resultado de um desses estudos, inferiu-se que a presença de apenas uma isoforma $\varepsilon 4$ implicaria aumento de 2,5 vezes na probabilidade de o paciente apresentar ilusões, ao passo que ao apresentar duas isoformas $\varepsilon 4$, a probabilidade aumentaria 5,6 vezes, mesmo levando-se em conta aspectos como a diferença de sexo, etnia, grau de instrução e duração da doença. Como resultado, tem-se que a presença de um ou mais alelos $\varepsilon 4$ é um fator importante na predi- ção de ilusões na DA, o que também nos auxilia a traçar uma linha cada vez mais consistente de ligação entre a apoE e DA (Scarmeas et al., 2002). No entanto, Yip et al. (2002) sugerem que estes achados devem ser questionados, pois na idade de manifestação da demência na DA, o nível de apoE já se apresenta em significativo decréscimo. Para outros sintomas, como distúrbios de comportamento e depressão, não foram encontradas evidências que possam associá-las à apoE ou a outros fatores genéticos (Scarmeas et al., 2002).

$O$ peso da presença do alelo $\varepsilon 4$ no desenvolvimento da DA parece variar de acordo com a idade, a etnia e o sexo. A idade possui um papel particularmente importante no desenvolvimento de DA. O risco de desenvolver a doença parece aumentar com a idade até certo ponto, a partir do qual o mesmo cai vertiginosamente. A presença de dois alelos $\varepsilon 4$ é responsável por uma grande diminuição na idade de início da doença, enquanto que a presença de apenas um alelo $\varepsilon 4$ é responsável por uma diminuição menos acentuada (revisão em Panza et al., 2002). Um estudo recente avaliou o grau de risco conferido pelos diferentes genótipos de apoE entre indivíduos da mesma faixa etária. Os resultados mostram que indivíduos com idade de 80 anos que apresentam $\varepsilon 3 / \varepsilon 4$ possuem uma taxa de incidência de DA aumentada em 3,4 vezes em relação a indivíduos $\varepsilon 3 / \varepsilon 3$. Indivíduos que são $\varepsilon 4 / \varepsilon 4$ possuem taxa de incidência aumentada 9,4 , enquanto os que possuem a isoforma $\varepsilon 2$ apresentam redução de $43 \%$ no risco apresentado por um indivíduo $\varepsilon 3 / \varepsilon 3$, sugerindo um papel protetor do alelo $\varepsilon 2$ (Ewbank, 2002).

A importância dos alelos de apoE no desenvolvimento da DA parece ser consistente mesmo entre os diferentes grupos étnicos. Povos caribenhos descendentes de hispânicos apresentam uma alta taxa de associação entre DA e apoE $\varepsilon 4$ (Goldstein et al., 2001); parentes de primeiro grau de indivíduos classificados como afro-americanos possuem um risco acumulado maior (sexo, etnia, grau de escolaridade etc.) de desenvolver DA do que parentes de mesmo grau de indivíduos classificados como caucasianos (Kim et al., 2002); um estudo feito na região sudeste do Brasil identificou uma forte associação entre apoE $\varepsilon 4$ e DA. O alelo $\varepsilon 4$ foi encontrado com uma freqüência de $39 \%$ em portadores da DA, valor cerca de quatro vezes maior que o encontrado nos indivíduos saudáveis da mesma localidade (de-Andrade et al., 2000). Um outro estudo com 126 indivíduos brasileiros (Souza et al., 2003) mostrou que a freqüência do alelo apoE $\varepsilon 2$ foi consideravelmente menor no grupo de pacientes com DA (1\%; $\mathrm{n}=68$ ); as freqüências do alelo apoE $\varepsilon 3$ e do genótipo 
apoE $\varepsilon 3 / \varepsilon 3$ foram maiores nos controles ( $84 \%$ e $72 \%$, respectivamente; $n=58$ ), enquanto as freqüências do alelo apoE $\varepsilon 4$ e do genótipo apoE $\varepsilon 3 / \varepsilon 4$ foram maiores nos indivíduos com DA (25\% e $41 \%$, respectivamente). Uma somatória dos achados destes dois trabalhos, os mais recentes que avaliaram a distribuição de alelos de apoE na população brasileira, baseada em 91 pacientes com DA e 258 controles, oferece uma distribuição das freqüências alélicas e genotípicas em nossa população (Tabela 1).

Tabela 1 - Distribuição das freqüências alélicas e genotípicas do gene apoE na população brasileira, em indivíduos com a DA e indivíduos-controle, com base na somatória de genótipos definidos em dois estudos (de-Andrade et al., 2000; Souza et al., 2003)

\begin{tabular}{lcc} 
Alelos & \multicolumn{2}{c}{$\begin{array}{c}\text { Número de indivíduos (frequiência \%) } \\
\text { Cacientes com DA }\end{array}$} \\
\hline apoE $\varepsilon 2$ & $5(2,75)$ & $35(6,78)$ \\
apoE $\varepsilon 3$ & $125(68,68)$ & $399(77,33)$ \\
apoE $\varepsilon 4$ & $52(28,57)$ & $82(15,89)$ \\
Genótipos & Número de indivíduos & (frequiência \%) \\
& Pacientes com DA & Controles \\
apoE $\varepsilon 2 / \varepsilon 2$ & $0(0)$ & $1(0,39)$ \\
apoE $\varepsilon 2 / \varepsilon 3$ & $2(2,20)$ & $27(10,47)$ \\
apoE $\varepsilon 2 / \varepsilon 4$ & $2(2,20)$ & $6(2,32)$ \\
apoE $\varepsilon 3 / \varepsilon 3$ & $44(48,35)$ & $160(62,02)$ \\
apoE $\varepsilon 3 / \varepsilon 4$ & $36(39,56)$ & $52(20,16)$ \\
apoE $\varepsilon 4 / \varepsilon 4$ & $7(7,69)$ & $12(4,64)$ \\
Total & 91 & 258
\end{tabular}

Apesar da contradição existente entre muitos estudos atuais, sabemos que o polimorfismo de apoE é apenas um dos diversos fatores genéticos envolvidos na DA. A apoE desempenha um papel importante na instauração da DA, mas o simples fato de um indivíduo possuir, mesmo que em homozigose, a isoforma $\varepsilon 4$, não implica necessariamente o desenvolvimento da doença. Outro fato importante é que a isoforma $\varepsilon 4$ não parece estar diretamente relacionada com a DA precoce, sendo mais freqüentemente associada com a forma tardia e esporádica da doença (Yoshizawa et al., 1994).

Embora o estudo da genética de DA esteja apenas em seu começo, os resultados já obtidos permitem começar a decifrá-la, compreendendo alguns de seus fatores de risco e sua epidemiologia, permitindo vislumbrar o desenvolvimento de novos mecanismos de abordagem e combate à doença, quer sejam através da genética, quer sejam através de estudos farmacológicos (Cacabelos, 2002).

\section{Perspectivas no estudo de apoE e DA}

Diversos estudos confirmam que a simples presença da isoforma $\varepsilon 4$ de apoE não é suficiente para o desenvolvimento da DA. No entanto, não restam dúvidas de que os alelos da apoE são fatores importantes que, de acordo com sua variação, têm o efeito de agonistas ou antagonistas no processo de instauração da doença. Neste sentido, alguns grupos vêm estudando o papel dos polimorfismos da região promotora do gene da apoE $\varepsilon 4$ e sua influência no desenvolvimento da DA. Polimorfismos na região promotora dos genes podem alterar a sua transcrição, gerando diferentes quantidades do RNA mensageiro e da respectiva proteína. Na região promotora do gene da apoE, já foram identificados polimorfismos nas regiões $-219 \mathrm{G} / \mathrm{T},-427 \mathrm{C} / \mathrm{T}$ e $-491 \mathrm{~A} / \mathrm{T}$.

Artiga et al. (1998) destacaram a importância da variante alélica -491C e do haplótipo [- 491A427C] no aumento do risco de desenvolver DA, porém, esse mesmo grupo não confirmou essa associação em outro estudo (Roks et al., 1998). Outro estudo refere ter encontrado uma pequena, porém significativa, alteração na concentração da apoE no plasma, independentemente do genótipo para essa característica. Como resultado desse estudo, foi observado que o polimorfismo - $491 \mathrm{~A} / \mathrm{T}$ apresenta um papel independente do genótipo para apoE nos níveis dessa apolipoproteína no plasma sangüíneo, mas não independente para o risco de desenvolver DA (Beyer et al., 2002). Esses resultados foram confirmados por um estudo posterior que acrescentou que o polimorfismo na região - 491 é causado pela substituição de uma timina por uma adenina, além de acrescentar a importância da região - 219 no desenvolvimento de Alzheimer como fator de risco, sendo que esta região passa a desempenhar um papel cada vez mais significativo com o avanço da idade.

Embora o estudo da genética da DA já esteja avançado, diversos passos ainda são necessários na elucidação de seus mecanismos de instauração, desenvolvimento e fatores de risco associados, quer sejam eles genéticos ou ambientais. Com este avanço, os achados da genética poderão ser utilizados no diagnóstico precoce da doença, no seu tratamento ou mesmo na elaboração de estratégias de prevenção. Devemos ressaltar que há um consenso na comunidade científica: a determinação das isoformas de apoE ainda é insuficiente como método diagnóstico. É precipitado afirmar que um indivíduo assintomático irá desenvolver a doença, baseado apenas no seu genótipo de apoE. 


\section{Referências bibliográficas}

de-Andrade, F.M.; Larrandaburu, M.; Callegari-Jaceues, S.M.; Gastaldo, G.; HuTz, M.H. - Association of apolipoprotein E polymorphism with plasma lipids and Alzheimer's disease in a Southern Brazilian population. Braz J Med Biol Res 33: 529-37, 2000.

Artiga, M.J.; Bullido, M.J.; Frank, A.; Sastre, I.; Recuero, M.; Garcia, M.A.; Lendon, C.L.; Han, S.W.; Morris, J.C.; Vazouez, J.; Goate, A.; VAldivieso, F. - Risk for Alzheimer's disease correlates with transcriptional activity of the apoE gene. Hum Mol Genet 7: 1887-92, 1998.

Bales, K.R.; Verina, T.; Dodel, R.C.; Du, Y.; Altstiel, L.; Bender, M.; Hyslop, P.; Johnstone, E.M.; Little, S.P.; Cummins, D.J.; Piccardo P.; Ghetti B.; PAul, S.M. - Lack of apolipoprotein E dramatically reduces amyloid beta-peptide deposition. Nat Genet 17: 2634, 1997.

Bales, K.R.; Verina, T.; Cummins, D.J.; Du, Y.; Dodel, R.C.; Saura, J.; Fishman, C.E.; DeLong, C.A.; Piccardo, P.; Petegnief, V.; Ghetti, B.; PAUL, S.M. - Apolipoprotein E is essential for amyloid deposition in the APP $(V 717 \mathrm{~F})$ transgenic mouse model of Alzheimer's disease. Proc Natl Acad Sci U S A 96: 15233-8, 1999.

Beyer, K.; Lao, J.I.; Gomez, M.; Riutort, N.; Latorre, P.; Mate, J.L.; Ariza, A. - Identification of a protective allele against Alzheimer disease in the apoE gene promoter. Neuroreport 13: 1403-5, 2002.

Boschert, U.; Merlo-Pich, E.; Higgins, G.; Roses, A.D.; Catsicas, S. Apolipoprotein E Expression by Neurons Surviving Excitotoxic Stress. Neurobiol Dis 6: 508-14, 1999.

Boyles, J.K· Pitas, R.E · Wilson, E* Mahley, R.W · TAylor, J.M. Apolipoprotein E associated with astrocytic glia of the central nervous system and with nonmyelinating glia of the peripheral nervous system. J Clin Invest 76: 1501-13, 1985.

Cacabelos, R. - Pharmacogenomics in Alzheimer's disease. Mini Rev Med Chem : 59-84, 2002.

Corbo, R.M.; ScAcchi, R. - Apolipoprotein E (apoE) allele distribution in the world: is apoE4 a 'thrifty' allele? Ann Hum Genet 63: 301-10, 1999.

Corder, E.H.; Lannfelt, L.; Bogdanovic, N.; Fratiglioni, L.; Mori, H. The role of apoE polymorphisms in late-onset dementias. Cell Mol Life Sci 54: 928-34, 1998.

Corder, E.H.; Saunders, A.M.; Strittmatter, W.J.; Schmechel, D.E.; Gaskell, P.C.; Small, G.W.; Roses, A.D.; Haines, J.L.; PericaK-Vance, M.A. Gene dose of apolipoprotein E type 4 allele and the risk of Alzheimer's disease in late onset families. Science 261: 921-3, 1993.

Czyzewski, K.; Pfeffer, A.; Barcikowska, M. - [Apolipoprotein E function in the nervous system]. Neurol Neurochir Pol 32: 125-32, 1998.

DAs, H.K.; MCPherson, J • BRUns, G.A. ET AL - Isolation, characterization, and mapping to chromosome 19 of the human apolipoprotein E gene. J Biol Chem 260: 6240-7, 1985.

Elshourbagy, N.A.; Liao, W.S.; Mahley, R.W. et Al. - Apolipoprotein E mRNA is abundant in the brain and adrenals, as well as in the liver, and is present in other peripheral tissues of rats and marmosets. Proc Natl Acad Sci USA 82: 203-7, 1985.

EwBank, D.C. - A multistate model of the genetic risk of Alzheimer's disease. Exp Aging Res 28: 477-99, 2002.

Fullerton, S.M.; Clark, A.G.; Weiss, K.M. et Al. - Apolipoprotein E variation at the sequence haplotype level: implications for the origin and maintenance of a major human polymorphism. Am J Hum Genet 67: 881-900, 2000.

Goldstein, F.C.; Ashley, A.V.; Gearing, M.; Hanfelt, J.; Penix, L.; FreedMAN L.J.; LEVEY, A. I. - Apolipoprotein E and age at onset of Alzheimer's disease in African American patients. Neurology 57: 1923-5, 2001.

KIM, J.M.; ShIN, I.S.; Yoon, J.S. - Apolipoprotein E among Korean Alzheimer's disease patients in community-dwelling and hospitalized elderly samples. Dement Geriatr Cogn Disord 13: 119-24, 2002

Laws, S.M.; Hone, E.; GAndy, S. ET AL. - Expanding the association between the apoE gene and the risk of Alzheimer's disease: possible roles for apoE promoter polymorphisms and alterations in apoE transcription. J Neurochem 84: 1215-36, 2003.

LIN, C.T.; XU, Y.F.; WU, J.Y. ET AL. - Immunoreactive apolipoprotein E is a widely distributed cellular protein. Immunohistochemical localization of apolipoprotein $\mathrm{E}$ in baboon tissues. J Clin Invest 78: 947-58, 1986.

Martins, R.N.; Clarnette, R.; Fisher, C. et Al. - ApoE genotypes in Australia: roles in early and late onset Alzheimer's disease and Down's syndrome. Neuroreport 6: 1513-6, 1995.

Mensenkamp, A.R.; Jong, M.C.; van Goor, H.; van Luyn, M.J.; Bloks, V.; Havinga, R.; Voshol, P.J.; Hofker, M.H.; van Dijk, K.W.; Havekes, L.M.; KuIPERS, F. - Apolipoprotein E participates in the regulation of very low density lipoprotein-triglyceride secretion by the liver. J Biol Chem 274: 35711-8, 1999.

Nakai, M.; Kawamata, T.; Taniguchi, T.; Maeda, K.; Tanaka, C. - Ex pression of apolipoprotein E mRNA in rat microglia. Neurosci Lett 211: 41-4, 1996.

Nickerson, D.A.; TAylor, S.L.; Fullerton, S.M. et Al. - Sequence diversity and large-scale typing of SNPs in the human apolipoprotein E gene. Genome Res 10: 1532-45, 2000

Olaisen, B.; Teisberg, P.; Gedde-Dahl, T. Jr. - The locus for apolipoprotein E (apoE) is linked to the complement component C3 (C3) locus on chromosome 19 in man. Hum Genet 62: 233-6, 1982

Paik, Y.K.; Chang, D.J.; Reardon, C.A.; Davies, G.E.; Mahley, R.W.; TaYLOR, J.M. - Nucleotide sequence and structure of the human apolipoprotein E gene. Proc Natl Acad Sci USA 82: 3445-9, 1985 .

Panza, F.; Solfrizzi, V.; D'Introno, A.; Capurso, C.; Colacicco, A.M.; Torres, F.; Altomare, E.; Capurso, A. - Genetics of late-onset Alzheimer's disease: vascular risk and beta-amyloid metabolism Recent Prog Med 9: 489-97, 2002.

Pitas, R.E.; Boyles, J.K.; Lee, S.H.; Foss, D.; Mahley, R.W. - Astrocytes synthesize apolipoprotein E and metabolize apolipoprotein E- containing lipoproteins. Biochim Biophys Acta 917: 14861, 1987 .

Puglielli, L.; Tanzi, R.E.; Kovacs, D.M. - Alzheimer's disease: the cholesterol connection. Nat Neurosci 6: 345-51, 2003.

Rall, S.C. Jr.; Weisgraber, K.H.; InNerarity, T.L.; et Al. - Structural basis for receptor binding heterogeneity of apolipoprotein $\mathrm{E}$ from type III hyperlipoproteinemic subjects. Proc Natl Acad Sci US A 79: 4696-700, 1982a.

Rall, S.C. Jr.; Weisgraber, K.H.; Mahley, R.W.; et Al. - Human apolipoprotein E. The complete amino acid sequence. $J$ Biol Chem 257: 4171-8, 1982b.

Rocchi, A.; Pellegrini, S.; Siciliano, G.; Murri, L. - Causative and susceptibility genes for Alzheimer's disease: a review. Brain Research Bulletin 61: 1-24, 2003.

Roks, G.; Cruts, M.; Bullido, M.J.; Backhovens, H.; Artiga, M.J.; Hofman, A.; Valdivieso, F.; Van Broeckhoven, C.; Van Duijn, C.M. - The -491 $\mathrm{A} / \mathrm{T}$ polymorphism in the regulatory region of the apolipoprotein E gene and early-onset Alzheimer's disease. Neurosci Lett 258: 65-8, 1998.

Roses, A.D.; Gilbert, J.; Xu, P.T.; Sullivan, P.; Popko, B.; Burkhart, D.S.; Christian-Rothrock, T.; Saunders, A.M.; Maeda, N.; Schmechel, D.E. - Cis-acting human ApoE tissue expression element is associated with human pattern of intraneuronal ApoE in transgenic mice. Neurobiol Aging 19: S53-8, 1998.

SAunders, A.M.; Schmader, K.; Breitner, J.C.S.; Benson, M.D.; Brown, W.T.; Goldfarb, L.; Goldgaber, D.; Manwaring, M.G.; Szymanski, M.H.; 
McCown, N.; Dole, K.C.; Schmechel, D.E.; Strittmatter, W.J.; PericaKVANCE, M.A.; Roses, A.D. - Apolipoprotein E epsilon-4 allele distributions in late-onset Alzheimer's disease and in other amyloid-forming diseases. Lancet 342: 710-1, 1993.

Scarmeas, N.; Brandt, J.; Albert, M.; Devanand, D.P.; Marder, K.; Bell, K.; Ciappa, A.; Tycko, B.; Stern, Y. - Association between the apoE genotype and psychopathologic symptoms in Alzheimer's disease. Neurology 58: 1182-8, 2002.

Souza, D.R.; de Godoy, M.R.; Hotta, J.; Tajara, E.H.; Brandão, A.C.; Pinheiro Junior, S.; Tognola, W.A.; DOS Santos, J.E. - Association of apolipoprotein E polymorphism in late-onset Alzheimer's disease and vascular dementia in Brazilians. Braz J Med Biol Res 36: 919-23, 2003.

TANZi, R.E.; Bertram, L. - New frontiers in Alzheimer's disease genetics. Neuron 32: 181-4, 2001.

Utermann, G.; Pruin, N.; Steinmetz, A. - Polymorphism of apolipoprotein E. III. Effect of a single polymorphic gene 1ocus on plasma lipid levels in man. Clin. Genet. 15: 63-72, 1979.

Utermann, G.; Langenbeck, U.; Beisiegel, U.; et al. - Genetics of the apolipoprotein E system in man. Am J Hum Genet 32: 339-47, 1980.
Weisgraber, K.H.; InNerarity, T.L.; Mahley, R.W. - Abnormal lipoprotein receptor-binding activity of the human $\mathrm{E}$ apoprotein due to cysteine-arginine interchange at a single site. J Biol Chem 257: 2518-21, 1982.

Weisgraber, K.H.; Rall, S.C., JR.; Mahley, R.W. - Human E apoprotein hete-rogeneity: cysteine-arginine interchanges in the aminoacid sequence of the apo-E isoforms. J Biol Chem 256: 907783, 1981 .

Xu, P.T.; Gilbert, J.R.; Qiu, H.L.; Ervin, J.; Rothrock-Christian, T.R.; Hulette, C.; SChMeChel, D.E. - Specific regional transcription of apolipoprotein E in human brain neurons. Am J Pathol 154: 601-11, 1999.

Yip, A.G.; Brayne, C.; Easton, D.; Rubinsztein, D.C. - Apolipoprotein E4 is only a weak predictor of dementia and cognitive decline in the general population. J Med Genet 39: 639-43, 2002.

Yoshizana, T.; Yamakawa-Kobayashi, K.; Komatsuzaki, Y.; Arinami, T. Oguni, E.; Mizusawa, H.; Shoji, S.; Hamaguchi, H. - Dose-dependent association of apolipoprotein $\mathrm{E}$ allele epsilon-4 with late-onset, sporadic Alzheimer's disease. Ann Neurol 36: 656-9, 1994. 